\title{
Common Genetic Contributions to Alcohol and Cannabis Use and Dependence Symptomatology
}

\author{
Carolyn E. Sartor, Julia D. Grant, Kathleen K. Bucholz, Pamela A. F. Madden, Andrew C \\ Heath, Arpana Agrawal, John B. Whitfield, Dixie J. Statham, Nicholas G. Martin, and \\ Michael T. Lynskey
}

\begin{abstract}
Background: Despite mounting evidence that use of and dependence on alcohol and cannabis are influenced by heritable factors, the extent to which heritable influences on these phenotypes overlap across the 2 substances has only rarely been explored. In the current study, we quantified cross-substance overlap in sources of variance and estimated the degree to which within-substance associations between use and dependence measures are attributable to common genetic and environmental factors for alcohol and cannabis.

Methods: The sample was comprised of 6,257 individuals $(2,761$ complete twin pairs and 735 singletons) from the Australian Twin Registry, aged 24 to 36 years. Alcohol and cannabis use histories were collected via telephone diagnostic interviews and used to derive an alcohol consumption factor, a frequency measure for cannabis use, and DSM-IV alcohol and cannabis dependence symptom counts. Standard genetic analyses were conducted to produce a quadrivariate model that provided estimates of overlap in genetic and environmental influences across the 4 phenotypes.

Results: Over $60 \%$ of variance in alcohol consumption, cannabis use, and cannabis dependence symptoms, and just under $50 \%$ of variance in alcohol dependence (AD) symptoms were attributable to genetic sources. Shared environmental factors did not contribute significantly to the 4 phenotypes. Nearly complete overlap in heritable influences was observed for withinsubstance measures of use and dependence symptoms. Genetic correlations across substances were 0.68 and 0.62 for use and dependence symptoms, respectively.

Conclusions: Common heritable influences were evident for alcohol and cannabis use and for $\mathrm{AD}$ and cannabis dependence symptomatology, but findings indicate that substance-specific influences account for the majority of the genetic variance in the cannabis use and dependence phenotypes. By contrast, the substantial correlations between alcohol use and AD symptoms and between cannabis use and cannabis dependence symptoms suggest that measures of heaviness of use capture much of the same genetic liability to alcohol- and cannabis-related problems as dependence symptomatology.
\end{abstract}

Key Words: Alcohol Dependence, Cannabis Dependence, Genetics, Twins.

\section{INTRODUCTION}

Alcohol and Cannabis: Use, Dependence, and Comorbidity

Seventy-five percent of U.S. adults over the age of 18 have consumed alcohol (National Center for Health Statistics, 2009). One in three of those individuals have met criteria for at least 1 dependence symptom over their lifetimes (McBride

From the Department of Psychiatry (CES, JDG, KKB, PAFM, $A C H, A A, M T L)$, Washington University School of Medicine, St Louis, Missouri; Genetic Epidemiology Unit (JBW, DJS, NGM), Queensland Institute of Medical Research, Brisbane, Queensland, Australia; and Faculty of Arts and Sciences (DJS), University of the Sunshine Coast, Queensland, Australia

Received for publication July 2, 2009; accepted October 23, 2009.

Reprint requests: Carolyn E. Sartor, PhD, Department of Psychiatry, Washington University School of Medicine, 660 South Euclid Avenue, Campus Box 8134, St Louis, MO 63110; Fax: 314-286-2213; E-mail:sartorc@psychiatry.wustl.edu

Copyright (c) 2009 by the Research Society on Alcoholism.

DOI: $10.1111 / j .1530-0277.2009 .01120 . x$ et al., 2009) and the evidence suggests there is a dose-response effect between levels of consumption and risk of dependence. Alcohol use disorder symptomatology is in fact so strongly associated with heaviness of use that integration of a quantifiable indicator of excessive consumption into diagnostic criteria has been proposed (Li, 2008; Li et al., 2007; O'Neill et al., 2001; Saha et al., 2007). Although less commonly used than alcohol, cannabis has long been the most frequently used illicit drug (Johnston et al., 2003; Substance Abuse and Mental Health Services Administration, 2002), with estimated prevalence of lifetime (i.e., ever) use of 20.5 to $42.8 \%$ for adults (Grucza et al., 2007) and $47.4 \%$ for 12th graders (Johnston et al., 2009) in the U.S. DSM-IV cannabis dependence criteria are met by $10 \%$ to $18 \%$ of cannabis users (Anthony et al., 1994; Hall and Pacula, 2003; Teesson et al., 2006) and in a recent study of adolescent cannabis users, over one third had at least 1 dependence symptom (Nocon et al., 2006). Like alcohol, severity of symptomatology increases steadily with heaviness of use (Coffey et al., 2002; Nocon et al., 2006). For example, in an Australian sample of young adults, $13 \%$ of 
those who used cannabis once or twice per week met cannabis dependence criteria, compared with $53 \%$ of those who used cannabis 3 or more times per week (Coffey et al., 2002).

Lifetime history of alcohol use is nearly universal among adolescents and adults who have used cannabis (Degenhardt and Hall, 2003; Pape et al., 2009; Sartor et al., 2009). As might be expected, problem drinking also frequently co-occurs with cannabis dependence symptomatology: AD criteria are met by approximately $70 \%$ of individuals with cannabis dependence (Agosti et al., 2002; Stinson et al., 2006). Likelihood of developing cannabis dependence is similarly elevated in alcohol-dependent individuals: Degenhardt and Hall (2003) reported that the odds of meeting cannabis dependence criteria were 5.81 times higher in those who met criteria for AD than in those who did not. Many of the same risk factors associated with alcohol-related problems have also been linked to cannabis use and related symptomatology. For example, externalizing disorders, deviant peer affiliation and family history of substance use disorders are all welldocumented correlates of problem use of both alcohol and cannabis (Elkins et al., 2007; Fergusson et al., 2002, 2008; Gillespie et al., 2009; Hayatbakhsh et al., 2008; Kuperman et al., 2001; Marshal et al., 2003; Monshouwer et al., 2006; Slutske et al., 1998), suggesting that the association may be attributable at least in part to common sources of risk.

\section{Genetic Influences on Alcohol and Cannabis Use and Related Symptomatology}

The influence of genes on alcohol dependence (AD) and related symptomatology is well established. Results from twin studies indicate that approximately half of the variance in AD $(50 \%$ to $60 \%)$ is accounted for by genetic factors and heritability does not vary significantly by gender (Heath et al., 1997; Knopik et al., 2004; Reed et al., 1996; True et al., 1996; van den Bree et al., 1998b). Twin studies have also produced evidence for genetic contributions to alcohol consumption (Grant et al., 2009; Heath and colleagues 1991; King et al., 2005; Whitfield et al., 2004), but the literature on consumption phenotypes is more limited than the AD literature and heritability estimates appear to vary by both age and sex. An early study by Heath and colleagues (1991) found that in females $57 \%$ of variance in quantity consumed was attributable to genetic factors, but results were less clear in males: an equally good fit was found for models in which $24 \%$ and $61 \%$ of variance was accounted for by genetic factors. In a longitudinal study by King and colleagues (2005), heavy drinking was assessed at ages 17 and 20 and heritability in females was estimated at $18 \%$ and $30 \%$, respectively; for males heritability was $57 \%$ at age 17 and $39 \%$ at age 20 .

Genetically informative studies of cannabis use and related symptomatology have consistently produced evidence for substantial genetic influences on both use and dependence phenotypes (Agrawal and Lynskey, 2006). In a sample of female twins, Kendler and Prescott (1998) found that 79\% of variance in heavy cannabis use and $62.3 \%$ of variance in cannabis dependence could be explained by genetic factors. A twin study of illicit drug use in males by the same group produced nearly identical heritability estimates: $84 \%$ for heavy use and 58\% for dependence (Kendler et al., 2000). Similar results have been reported in 2 other twin studies: Lynskey and colleagues (2002) found that $64.3 \%$ of variance in heavy use and $53 \%$ to $68 \%$ of variance in dependence was attributable to genetic factors and van den Bree and colleagues (1998a) estimated heritability of dependence at 44.7\% .

Despite mounting evidence that both use of and dependence on alcohol and cannabis are influenced by heritable factors, there is relatively little information on the extent to which heritable influences on these phenotypes overlap across the 2 substances. Results from one such study, which examined use and problem use of alcohol, cannabis and cigarettes in an adolescent twin sample, revealed a genetic correlation of 0.62 between problem alcohol use and problem cannabis use (Young et al., 2006). An investigation of cannabis dependence symptoms and AD symptoms along with conduct disorder in an all-male adult twin sample identified a common genetic factor that accounted for $44.7 \%$ of variance in AD symptoms, but only $7.6 \%$ of variance in cannabis dependence symptoms (True et al., 1999). Another study using this same sample examined AD and cannabis dependence in combination with nicotine dependence and found that $42.4 \%$ of the variance in AD and $33.7 \%$ of the variance in cannabis dependence was attributable to a shared genetic factor (Xian et al., 2008). By contrast, when examined in combination with cocaine, caffeine, and nicotine dependence in a study of male and female adult twins, AD and cannabis dependence loaded on 2 different-but correlated $(r=0.82)$-genetic factors, one encompassing the illicit substances, the other comprised of the licit substances (Kendler et al., 2007). Taken together, the literature suggests that there are some common genetic contributions to alcohol and cannabis-related phenotypes, but differences in samples and measurements of outcomes across studies do not allow for clear conclusions to be drawn about the magnitude of those overlapping influences. (Differences in the manifestation of genetic risk by developmental stage or gender, for example, could explain variations in findings, as might the shift in estimates of overlapping influences specific to alcohol and cannabis that can result from the addition of other phenotypes to genetic models.)

Furthermore, the limited research in this area has not addressed the similarities (and distinctions) in the underlying variance structures of use and dependence for cannabis - and only rarely for alcohol (Grant et al., 2009; Whitfield et al., 2004). Such a pursuit is highly relevant to gene association studies, as a large degree of genetic overlap between heaviness of use and dependence symptoms suggests that gene-finding studies for 1 phenotype can be directed by results from investigations of the other, perhaps even allowing for the integration of findings from studies of heavy use with those focused on dependence. The significant implications for etiological models of alcohol and cannabis dependence and the utility of global versus substance-specific intervention strategies further 
highlight the importance of investigating commonality in sources of influence on alcohol and cannabis use and related symptomatology.

The primary aim of our study was to determine the degree to which the (lifetime) co-occurrence of heavy alcohol and cannabis use and the comorbidity of alcohol and cannabis dependence symptomatology are explained by common heritable and environmental factors. In addition, we sought to quantify the overlap in sources of variance between consumption and dependence symptomatology in these 2 substances of abuse. To address these aims, a series of genetic models were fitted, producing estimates of the magnitude of genetic and environmental influences on alcohol consumption and dependence symptoms and cannabis use and dependence symptoms as well as the associations between these influences across the 4 phenotypes.

\section{MATERIALS AND METHODS}

\section{Participants}

The sample for the current study was comprised of members of the Australian Twin Registry. Twins born in Australia between 1964 and 1971 were recruited for the registry through school systems and mass media appeals. They were registered by their parents from 1980 to 1982 and initially contacted in 1989 through mailed questionnaires, then interviewed by telephone with standard psychiatric assessments between 1996 and 2000, when twins ranged in age from 24 to 36 years $($ mean $=29.9$ years). Approximately $73 \%$ of the targeted sample was successfully recruited into the study. Interviews were conducted with 6,257 individuals, representing 2,761 complete twin pairs and 735 respondents whose co-twins did not take part in the study. Breakdown by sex and zygosity of complete pairs are as follows: 698 monozygotic (MZ) female, $494 \mathrm{MZ}$ male, 513 dizygotic (DZ) female, $395 \mathrm{DZ}$ male, and $661 \mathrm{DZ}$ opposite sex twin pairs. Informed consent was obtained prior to the start of interviews, as approved by the Human Research Protection Offices of Washington University School of Medicine in the United States and the Queensland Institute of Medical Research in Australia. Additional details regarding sample ascertainment and data collection are reported in related publications (Heath et al., 2001; Lynskey et al., 2003; Nelson et al., 2002).

\section{Assessment}

Data were collected with a modified Semi-Structured Assessment for the Genetics of Alcoholism (SSAGA-OZ) (Bucholz et al., 1994; Hesselbrock et al., 1999), adapted for administration via telephone and updated for DSM-IV diagnostic criteria. Detailed histories of alcohol, cannabis and other substance use were gathered through SSAGA-based interviews, as were diagnostic criteria for substance use, mood, conduct, and anxiety disorders.

\section{Operationalization of Alcohol and Cannabis Use and Dependence Variables}

Alcohol Consumption. Alcohol consumption was measured as a composite of 5 indicators of heaviness of alcohol use over the lifetime, represented by a single factor derived through factor analysis (see Agrawal et al., 2009; Grant et al., 2009). Items comprising the factor and their corresponding factor loadings are as follows: density (i.e., quantity per week multiplied by frequency per week) of consumption during period of heaviest drinking (0.92), frequency of intoxication during period of heaviest drinking (0.68), maximum number of drinks ever consumed (0.76), frequency of heavy episodic drinking during period of heaviest drinking (0.79), and maximum number of drinks consumed before having an effect during period of heaviest drinking (0.73). (To adjust for skewness, the natural logarithm of the tolerance, density of heaviest use, and maximum drinks measures were used in the factor analysis.) The resulting continuous factor score was divided at $20 \%$ intervals (separately for females and males) and recoded into a 5-level ordinal variable. Alcohol use was nearly universal in the sample, with $98.9 \%$ of women and $98.7 \%$ of men reporting consumption of one or more drinks over the lifetime.

Cannabis Use. Cannabis use was operationalized as a 6-level categorical variable reflecting number of times used over the lifetime, with the lowest level being all nonusers and the remaining levels representing 20\% intervals (quintiles) for frequency of use. Given that males had higher rates of initiation $(68.8 \%$ of males versus $53.2 \%$ of females reported ever use) and reported heavier use, quintiles were calculated separately by sex. As in the case of alcohol consumption, the cannabis use variable is therefore an indicator of heaviness of use relative to same-sex peers. Frequency of use is reported by sex in Table 1.

Alcohol dependence symptoms were assessed in all individuals who reported ever drinking to intoxication or consuming alcohol at least once a month for 6 months or longer. Those who did not meet these criteria but reported some alcohol consumption were coded 0 for dependence symptoms.

Cannabis dependence symptoms were queried in all individuals who reported having used cannabis on at least a monthly basis (and 11 or more times over the lifetime) and coded 0 for those who had used cannabis but did not meet this minimum frequency. Drug dependence was not the primary focus of the interview, so to reduce respondent burden, an abbreviated cannabis dependence assessment based on the following 4 criteria was conducted: (i) using more frequently or over a longer period of time than intended, (ii) needing larger amounts to achieve the same effect (tolerance), (iii) continued use despite cannabis-induced emotional problems, and (iv) recurrent desire to cut down on use. (Analyses examining these modified criteria against full DSM-IV diagnostic criteria have yielded sensitivity and specificity estimates of 96.7 and $94.6 \%$, respectively; Lynskey et al., 2002.)

Dependence symptom variables for both alcohol and cannabis were operationalized as ordinal variables with 4 levels: $0,1,2$, and 3 or more symptoms. Distributions of alcohol and cannabis dependence symptoms are reported by sex in Table 2 .

\section{Data Analysis}

Twin Modeling. Data from MZ and DZ twins can be utilized to estimate the relative contribution of additive genetic (A), nonshared environmental (E), and either shared environmental (C) or nonadditive genetic (including dominance, and thus denoted as D) influences on population variation in a given behavior. $\mathrm{C}$ and $\mathrm{D}$ cannot

Table 1. Frequency of Cannabis Use by Sex

\begin{tabular}{lrllr}
\hline \multirow{2}{*}{ Females $n=3,436$} & & \multicolumn{2}{c}{ Males $n=2,772$} \\
\cline { 5 - 5 } Number of times used & & & \multicolumn{2}{c}{ Number of times used } \\
\cline { 5 - 6 } $1-2$ & $46.8 \%$ & & Never & $31.2 \%$ \\
$3-5$ & $13.2 \%$ & & $1-3$ & $15.3 \%$ \\
$6-12$ & $10.5 \%$ & & $4-10$ & $13.4 \%$ \\
$13-100$ & $9.2 \%$ & & $11-50$ & $13.6 \%$ \\
101 or more & $9.4 \%$ & & $51-500$ & $12.1 \%$ \\
& $10.9 \%$ & & 501 or more & $14.3 \%$ \\
\hline
\end{tabular}


Table 2. Rates of Alcohol and Cannabis Dependence Symptoms by Sex

\begin{tabular}{lccccc}
\hline & \multicolumn{2}{c}{ Alcohol } & & \multicolumn{2}{c}{ Cannabis } \\
\cline { 2 - 3 } \cline { 6 - 6 } $\begin{array}{l}\text { Dependence } \\
\text { symptoms }\end{array}$ & Females & Males & & Females & Males \\
\hline 0 & $n=3,422$ & $n=2,769$ & & $n=1,825$ & $n=1,904$ \\
1 & $35.0 \%$ & $17.2 \%$ & & $76.5 \%$ & $65.3 \%$ \\
2 & $26.3 \%$ & $23.5 \%$ & & $8.8 \%$ & $12.7 \%$ \\
$3+$ & $21.0 \%$ & $24.9 \%$ & & $6.7 \%$ & $9.1 \%$ \\
& $17.7 \%$ & $34.4 \%$ & & $8.1 \%$ & $12.9 \%$ \\
\hline
\end{tabular}

be jointly estimated when data from twins alone are used, so we fitted models incorporating $\mathrm{C}$ and $\mathrm{D}$ separately (i.e., $\mathrm{ACE}$ and $\mathrm{ADE}$ models) to the data.

In all genetic models, consumption/use was set to missing for a given substance if the individual reported 3 or more dependence symptoms for that substance (3 symptoms being the cut-off for a dependence diagnosis). This was the case for $17.7 \%$ of female drinkers and $34.4 \%$ of male drinkers and for $8.1 \%$ of female and $12.9 \%$ of male cannabis users, respectively. By using this technique (see Grant et al., 2009; Heath et al., 2002) we were able to examine the genetic correlation between heaviness of use and dependence symptomatology with the effects of dependence on consumption/use removed. (As dependence itself leads to increasing use, an artificial inflation of genetic correlation would occur if such an adjustment were not made.) All 4 measures were tested for assumptions of underlying multivariate normality. Fit statistics for the alcohol measures are available in Grant and colleagues (2009). For cannabisrelated measures, with the exception of $\mathrm{MZ}$ twins for cannabis use, all other groups showed evidence for multivariate normality.

Quadrivariate Model. A quadrivariate triangular decomposition (also known as a Cholesky decomposition) was fitted to assess the degree of overlap in genetic and environmental influences between alcohol consumption, AD symptomatology, cannabis use, and cannabis dependence symptomatology. Models were fitted in Mx (Neale et al., 2003) using full information maximum likelihood estimation with raw categorical data. Cannabis use and alcohol consumption variables were recoded into ordinal variables, as $\mathrm{Mx}$ requires that all variables be in the same format (and dependence symptoms are ordinal in nature). Thresholds were adjusted for age at the time of interview using 3 dummy variables to represent ages 28 to 29,30 to 31 , and 32 to 35 , with 24 to 27 years as the comparison group.

A series of sub-models examining the statistical significance of A $\mathrm{C}$, and $\mathrm{E}$ were compared with the full model to derive the best-fitting quadrivariate model. Sub-models were tested by calculating the difference between the $-2 \log$-likelihood fit of the full model and nested sub-model, which is distributed as chi-square for the given degrees of freedom.

\section{RESULTS}

\section{Level of Use and Risk for Dependence}

As seen in Fig. 1, a linear relationship between alcohol consumption and $\mathrm{AD}$ was observed in males, with each $20 \%$ incremental increase in heaviness of use corresponding to approximately a $10 \%$ increase in rates of $\mathrm{AD}$. By contrast, rates of $\mathrm{AD}$ in women increased dramatically from the 60th to 80 th percentile and from the 80 th percentile to the highest consumption levels (see Fig. 2). Although overall prevalence of $\mathrm{AD}$ in women was half that of men $(17.7 \%$ vs. $34.4 \%)$, the prevalence of $\mathrm{AD}$ in the heaviest drinking females was consid-

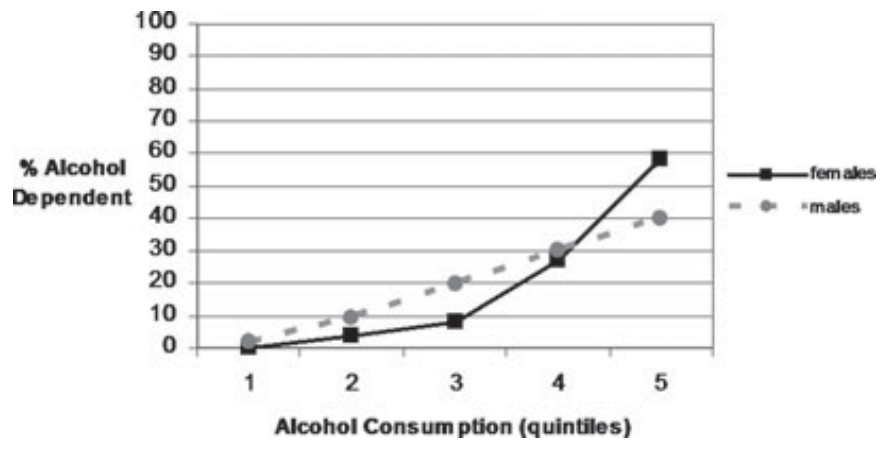

Fig. 1. Rates (\%) of alcohol dependence across varying levels of alcohol consumptions by sex.

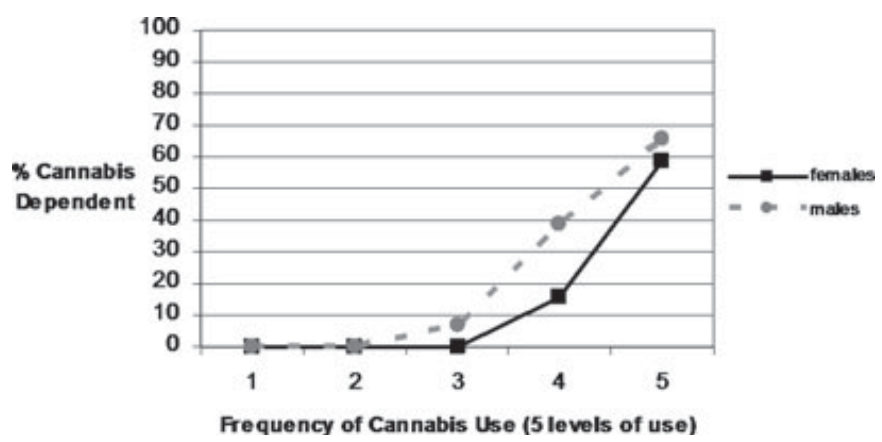

Fig. 2. Rates (\%) of cannabis dependence across varying levels of cannabis use by sex.

erably higher than in the heaviest drinking males (58.1\% vs. $39.9 \%$ ). The association between frequency of cannabis use and cannabis dependence in women paralleled the association in males (see Fig. 2). The prevalence of cannabis dependence was very low (0 to $6.9 \%$ ) for individuals in the low to average frequency use groups (i.e., fewer than 13 times for females and fewer than 51 times for males), but rates of cannabis dependence rose substantially as use increased to moderately high (15.4\% and $38.8 \%$ for females and males, respectively) and again to the highest frequency of use, at which $58.7 \%$ of females and $65.5 \%$ met full cannabis dependence criteria.

\section{Co-Occurrence of Alcohol Dependence and Cannabis Dependence}

Rates of cannabis dependence were substantially higher in individuals who met criteria for AD compared with those who did not. For women, the corresponding prevalences were $14.3 \%$ and $5.8 \%$ for $\mathrm{AD}$ positive and $\mathrm{AD}$ negative, respectively [odds ratio (OR): $2.71 ; 95 \%$ confidence interval (CI): 1.94-3.80]; for men, they were $20.4 \%$ and $7.6 \%$ (OR: 3.10 ; 95\% CI: $2.33-4.13)$.

\section{Quadrivariate Model}

The sub-models tested and their corresponding model fit statistics are reported in Table 3. Models 1 and 2 were full 
Table 3. Model Fit Statistics for Quadrivariate Cholesky Decomposition

\begin{tabular}{|c|c|c|c|c|c|}
\hline & Model & Compared with & $\Delta \chi^{2}$ & $\Delta \mathrm{df}$ & Significance \\
\hline 1 & Full ACE model, women and men equated ${ }^{\mathrm{a}}$ & - & - & - & - \\
\hline 2 & Full ADE model, women and men equated ${ }^{b}$ & - & - & - & - \\
\hline 3 & $\mathrm{AE}$ model, women and men equated ${ }^{\mathrm{C}}$ & Model 1 & 4.231 & 10 & 0.94 \\
\hline 4 & AE model, women and men estimated separately ${ }^{d}$ & Model 3 & -16.795 & -20 & 0.66 \\
\hline
\end{tabular}

a $-2 L L=48,134.641$.

b_-2LL $=48,138.872$.

${ }^{\mathrm{c}}$ Final model.

${ }^{d}$ Freeing female and male parameter estimation did not result in a significant improvement in fit.

Cholesky ACE and ADE models respectively. Parameter estimates for women and men were equated in these models. Because the log-likelihood of the ACE model was marginally better than that for the ADE model, the ACE model (Model 1) was selected for further examination. Model 3 tested an AE model with parameter estimates equated for women and men. This model resulted in a nonsignificant decrement in fit compared with Model 1, indicating that shared environmental influences were not significant. Model 3 therefore became the base model for additional analyses. In Model 4, we tested whether the parameters for women and men should be estimated separately. The improvement in fit when women and men were estimated separately was not significant, indicating that the parameter estimates can be equated across sex. Model 3 was therefore selected as the best-fitting model. (We were unable to estimate CIs because of the computational intensity of the calculations for the models, so we present only the point estimates for the proportion of variance attributable to $\mathrm{A}$ and $\mathrm{E}$ and for the correlations between $\mathrm{A}$ and $\mathrm{E}$ variance components.)

Under the best-fitting model (shown in Table 4), heritable influences accounted for over $60 \%$ of the variance in alcohol consumption, cannabis use, and cannabis dependence symptoms $(61.0 \%, 67.1 \%$, and $72.2 \%$, respectively). The heritability estimate was lowest - but still quite substantial - for AD symptoms: $46.8 \%$ of variance could be attributed to genetic factors. As noted above, we did not find evidence that shared environmental factors exert a significant influence on use or dependence symptomatology for alcohol or cannabis.

Table 4. Proportion of Variance Attributable to Additive Genetic and Environmental Sources for Alcohol and Cannabis Use and Dependence Symptoms ${ }^{\mathrm{a}}$

\begin{tabular}{lccccc}
\hline & \multicolumn{2}{c}{ Alcohol } & & \multicolumn{2}{c}{ Cannabis } \\
\cline { 2 - 3 } $\begin{array}{l}\text { Dependence } \\
\text { Source of variance }\end{array}$ & $\begin{array}{c}\text { Dependence } \\
\text { symptoms }\end{array}$ & Consumption & $\begin{array}{c}\text { Dependoms } \\
\text { symptoms }\end{array}$ & Use \\
\hline $\begin{array}{l}\text { Additive genetic } \\
\begin{array}{l}\text { Shared } \\
\text { environmental }\end{array}\end{array}$ & 0.468 & 0.610 & & 0.671 & 0.722 \\
$\begin{array}{c}\text { Nonshared } \\
\text { environmental }\end{array}$ & 0.532 & - & & - & - \\
\hline
\end{tabular}

aUnder the best-fitting quadrivariate model.
Phenotypic correlations among alcohol consumption, cannabis use, AD symptoms, and cannabis dependence symptoms are reported in Table 5. Additive genetic and unique environmental correlations among the 4 phenotypes are shown in Table 6. As is evident from Table 6, our results provide strong support for within-substance and cross-substance overlap in heritable influences. For alcohol consumption and dependence symptoms, $r_{\mathrm{G}}=0.953 ; 90 \%$ of the genetic variance in alcohol consumption was shared with AD symptoms. A similarly high overlap in heritable factors was observed for cannabis use and dependence symptoms: $r_{\mathrm{G}}=0.979$. Crosssubstance genetic correlations were more modest, but still highly significant. Genetic correlations of 0.675 and 0.613 were found for alcohol consumption and cannabis use and

Table 5. Phenotypic Correlations Between Alcohol and Cannabis Use and Dependence Symptoms

\begin{tabular}{|c|c|c|c|c|}
\hline & \multicolumn{2}{|c|}{ Alcohol } & \multicolumn{2}{|c|}{ Cannabis } \\
\hline & $\begin{array}{l}\text { Dependence } \\
\text { symptoms }\end{array}$ & Consumption & $\begin{array}{l}\text { Dependence } \\
\text { symptoms }\end{array}$ & Use \\
\hline \multicolumn{5}{|l|}{ Alcohol } \\
\hline Dep symptoms & - & & & \\
\hline Consumption & 0.600 & - & & \\
\hline \multicolumn{5}{|l|}{ Cannabis } \\
\hline Dep symptoms & 0.330 & 0.164 & - & \\
\hline Use & 0.426 & 0.440 & 0.847 & - \\
\hline
\end{tabular}

Dep, dependence.

Table 6. Additive Genetic and Unique Environmental Correlations ${ }^{a}$ Between Alcohol and Cannabis Use and Dependence Symptoms ${ }^{b}$

\begin{tabular}{|c|c|c|c|c|}
\hline & \multicolumn{2}{|c|}{ Alcohol } & \multicolumn{2}{|c|}{ Cannabis } \\
\hline & $\begin{array}{l}\text { Dependence } \\
\text { symptoms }\end{array}$ & Consumption & $\begin{array}{l}\text { Dependence } \\
\text { symptoms }\end{array}$ & Use \\
\hline \multicolumn{5}{|l|}{ Alcohol } \\
\hline Dep symptoms & - & 0.546 & 0.246 & 0.230 \\
\hline Consumption & 0.953 & - & 0.250 & 0.298 \\
\hline \multicolumn{5}{|l|}{ Cannabis } \\
\hline Dep symptoms & 0.613 & 0.655 & - & 0.889 \\
\hline Use & 0.621 & 0.675 & 0.979 & - \\
\hline
\end{tabular}

${ }^{\mathrm{a}}$ Genetic correlations are shown below the diagonal; correlations between unique environmental factors are shown above the diagonal. bUnder the best-fitting quadrivariate model.

Dep, dependence. 
for AD and cannabis dependence symptoms, respectively. As expected, given the high within-substance genetic correlation between use and dependence symptoms, genetic correlations were very similar for AD symptoms and cannabis use, $r_{\mathrm{G}}=0.621$ and for alcohol use and cannabis dependence symptoms, $r_{\mathrm{G}}=0.655$ as they were for cross-substance correlations of the same measure.

The proportion of genetic variance attributable to various sources was calculated using unstandardized path coefficients for the 4 phenotypes. (Coefficients for each pathway and the method for apportioning variance are reported in Fig. 3, which is included in Appendix 1.) A total of $90.9 \%$ of genetic variance in alcohol consumption was attributable to a source common to all 4 phenotypes. For cannabis dependence symptoms, $37.5 \%$ of genetic variance was attributable to influences common to all 4 phenotypes, 5.5\% to influences shared by alcohol consumption, cannabis dependence symptoms, and cannabis use (but not AD symptoms), and 57.0\% to influences shared with cannabis use. For cannabis use, the genetic variance was distributed as follows: $38.6 \%$ to influences common to all 4 phenotypes, $7.5 \%$ to influences shared by alcohol consumption, cannabis dependence symptoms, and cannabis use (but not AD symptoms), 50.0\% to influences shared by cannabis use and cannabis dependence symptoms (but not AD symptoms or alcohol consumption), and 3.9\% to phenotype-specific influences.

Analyses revealed both within- and cross-substance overlap in nonshared environmental factors as well, but unlike the associations observed with genetic factors, the degree of overlap differed substantially between alcohol and cannabis. The $r_{\mathrm{E}}$ for cannabis use and cannabis dependence symptoms was 0.889; for alcohol consumption and AD symptoms, $r_{\mathrm{E}}=0.546$. The cross-substance correlations were also more modest than those observed with genetic factors. Nonshared environmental influences on alcohol consumption and cannabis use were correlated at $r_{\mathrm{E}}=0.298$, AD symptoms and cannabis dependence symptoms at $r_{\mathrm{E}}=0.246$.

\section{DISCUSSION}

Our investigation of genetic and environmental contributions to use and dependence symptomatology for alcohol and cannabis revealed significant associations both across and within substances. On the phenotypic level, it produced further support for the strong link between heaviness of use and dependence symptoms for both substances as well as the high degree of comorbidity between AD and cannabis dependence. Through biometrical modeling we estimated heritability for each of the 4 phenotypes as well as both within- and cross-substance overlap in genetic and environmental influences on use and dependence symptoms, revealing the substantial role of common heritable factors in observed associations.

The correspondence between heaviness of alcohol consumption and level of risk for dependence in the current study is consistent with the dose-response effect described in the literature (Li et al., 2007; O'Neill et al., 2001; Saha et al., 2007). The overall trend did not vary by sex but the fact that nearly $60 \%$ of the heaviest drinking females compared with only $40 \%$ of the heaviest drinking males met AD criteria suggests some intriguing potential gender-related differences, for instance, that deviation from the norms for drinking behaviors confers greater risk for AD in women than in men. The parallel analysis with cannabis use and dependence symptomatology revealed a similar association that was consistent across sexes, with negligible rates of dependence for the lowest $60 \%$ and dramatic increases in prevalence for the next 2 levels of frequency of use. Although previous studies have measured heaviness of cannabis use in terms of number of days used per week or month, whereas we queried total number of times used, our results mirror the patterns reported in the literature: substantial elevations in risk occur as frequency of use moves from experimentation to moderate to heavy use (Coffey et al., 2002; Nocon et al., 2006). Our finding that $21.8 \%$ of women with $\mathrm{AD}$ and $27.1 \%$ of men with $\mathrm{AD}$ met cannabis dependence criteria also coincides with previous reports of elevated rates of cannabis dependence among alcohol-dependent individuals (Degenhardt and Hall, 2003; Xian et al., 2008).

Genetic modeling revealed that just under half of the variance in $\mathrm{AD}$ symptoms and over $60 \%$ of variance in the other 3 phenotypes could be accounted for by heritable sources of influence. Our estimated heritability of $46.8 \%$ for AD symptoms is slightly lower but within the expected range for dependence symptomatology. The majority of studies in this area have examined AD as a dichotomous outcome and produced heritability estimates of $50 \%$ to $60 \%$ (Heath et al., 1997; Knopik et al., 2004; Reed et al., 1996; True et al., 1996; van den Bree et al., 1998b). Far fewer genetically informative investigations have focused on heaviness of alcohol consumption and results have varied widely. Compared with the few published studies, our results fall at the high end of the range (Heath et al., 1991; King et al., 2005; Whitfield et al., 2004). By contrast, our findings for cannabis use and dependence symptoms closely match those from prior studies, which have estimated heritability at $45 \%$ to $85 \%$, with little distinction between estimates for use and dependence phenotypes (Agrawal and Lynskey, 2006; Kendler and Prescott, 1998; Kendler et al., 2000; Lynskey et al., 2002; van den Bree et al., 1998a). Also consistent with the existing literature (Heath et al., 1997; Kendler and Prescott, 1998; Kendler et al., 2000; Knopik et al., 2004), there was no evidence that the underlying variance structure for any of the 4 phenotypes under study varied significantly across sex.

We found a high degree of within-substance overlap in heritable influences on use and dependence. In contrast to the more moderate genetic correlation of 0.63 reported by our group for $\mathrm{AD}$ and average alcohol intake (Whitfield et al., 2004), we found that $90.9 \%$ of genetic contributions to heaviness of alcohol consumption (during heaviest period of use) were shared with AD symptoms (see also Grant et al., 2009). For cannabis phenotypes, the genetic correlation was 0.979 . The nearly perfect correlation between genetic contributions 
to use and genetic contributions to dependence for both alcohol and cannabis suggests that an indicator of heaviness of use may act as a proxy for dependence symptomatology (and vice versa). The implications for linkage and association studies of alcohol and cannabis use and dependence are far-reaching. Data collected on one of the 2 phenotypes can be highly informative for investigations focusing on the other phenotype; it may even be possible to integrate findings from studies examining heavy use with those examining dependence. Furthermore, the substantial genetic overlap in dependence symptomatology across the 2 substances suggests that samples ascertained based on AD risk capture a subpopulation at high genetic risk for cannabis dependence and thus can be useful in linkage and association studies of cannabis-related phenotypes as well.

With respect to individual-specific environmental influences, the degree of overlap across use and dependence symptoms was considerably higher for cannabis than for alcohol: nonshared environmental factors were correlated at 0.889 for cannabis versus 0.546 for alcohol. Given that nonshared environmental sources of variance include error, interpretations must be made with caution, but the higher strength of the association for the illicit drug raises some interesting possibilities. For example, it could be argued that use of a common licit drug is normative and is therefore shaped by different environmental factors than pathological use, whereas use of an illicit drug is somewhat more deviant and access is more limited, so the role of environmental factors in use and misuse of an illicit drug may not be as distinct.

In addition to the high within-substance correlations, we found a moderate degree of overlap in genetic influences across alcohol and cannabis in the respective use and dependence symptom phenotypes. Genetic factors were correlated at 0.675 for use and 0.613 for dependence symptomatology, but over half of inherited vulnerabilities to heavy use and to dependence symptoms were explained by substance-specific influences ( $57 \%$ for cannabis dependence symptoms and $53.9 \%$ for cannabis use) This etiological model is consistent with the high — but far from $100 \%$ - rate of co-occurrence for alcohol and cannabis-related problems (Degenhardt and Hall, 2003; Xian et al., 2008). The genetic correlation of 0.675 for use in our sample also coincides closely with the genetic correlation of 0.62 between problem alcohol use and problem cannabis use reported by Young and colleagues (2006), who examined these phenotypes in combination with nicotine dependence symptoms. Our estimates of overlap in heritable influences on dependence symptoms are highly consistent with Xian and colleagues (2008), who found that $42.4 \%$ of the variance in $\mathrm{AD}$ and $33.7 \%$ of the variance in cannabis dependence were accounted for by a shared genetic factor (that also loaded on nicotine dependence), but less so with 2 other known studies in this area. Notably, these 2 investigations included additional phenotypes not examined in studies that produced results more similar to ours, which likely influenced the identification of common factors in these models and thus the estimated overlap in genetic influences specific to
AD and cannabis dependence. For example, Kendler and colleagues' (2007) study in which 2 distinct but correlated genetic factors emerged, with alcohol loading on one and cannabis on the other, included cocaine and caffeine dependence. Similarly, True and colleagues' (1999) finding that the genetic factor common to AD symptoms and cannabis dependence symptoms accounted for only $7.6 \%$ of the total variance (and $17 \%$ of the genetic variance) in cannabis dependence symptoms may be attributable in part to the inclusion of conduct disorder in the models. In short, our study adds to a limited literature that has thus far produced mixed results regarding the degree of genetic overlap in AD and cannabis dependence symptomatology, with findings that match the highest estimates of common genetic influences to date (i.e., Xian et al., 2008).

In contrast to the high genetic correlations, the overlap across substances in nonshared environmental factors was negligible for both use and dependence symptoms $\left(r_{\mathrm{E}}=0.298\right.$ and 0.246 , respectively), indicating that the individual-specific environmental conditions that promote use and related problems vary across the 2 substances. This conclusion does not appear to be in keeping with evidence in the larger literature of common risk factors for alcohol and cannabis-related behaviors. The apparent discrepancy has 3 likely explanations. First, the low degree of overlap in nonshared environmental factors may be attributable to substance-specific measurement error. Second, many of the well-established risk factors, including externalizing behaviors and parental substance-related problems (Elkins et al., 2007; Fergusson et al., 2008; Hayatbakhsh et al., 2008; Kuperman et al., 2001; Monshouwer et al., 2006; Slutske et al., 1998) are themselves highly heritable (Knopik et al., 2005; Krueger et al., 2002; McGue et al., 2006; Sherman et al., 1997; Slutske et al., 1998). Moreover, they share a substantial proportion of genetic variance with alcohol and cannabis-related phenotypes (Hicks et al., 2004; Miles et al., 2002; Slutske et al., 1998; True et al., 1999), so they cannot be viewed as primarily environmental. Finally, heritability estimates - and consequently, genetic correlations - may also reflect gene-byenvironment interactions or gene-environment correlations (i.e., seeking out environments that promote behaviors for which one is at high genetic risk). Deviant peer affiliation, which has consistently been linked to alcohol and cannabisrelated problems (Fergusson et al., 2002; Gillespie et al., 2009; Marshal et al., 2003) is one such example of geneenvironment correlation: adolescents with externalizing problems, who are at high risk for substance misuse, seek out like-minded peers that encourage experimentation with substances. Exploration of gene-by-environment interplay in future studies is critical to fostering our understanding of the development of problem use of alcohol and cannabis.

\section{Limitations and Future Directions}

Our findings provide a foundation for further investigation of the genetics of alcohol- and cannabis-related phenotypes, 
both gene-mapping and studies of the interaction of inherited vulnerabilities with environmental influences that lead to these outcomes. However, there are possible limitations that need to be kept in mind. One is the potential for retrospective reporting biases to influence results, for example, for greater lag time from the event to the time of reporting to translate into systematic underreporting of use and symptoms (Carney et al., 1998; Stockwell et al., 2004). Given the relatively narrow age range (and thus the relatively narrow range in lag times) in the sample and our adjustment for age at the time of interview, it is unlikely that such a bias greatly influenced results, but reports from prospective studies would be more accurate. To the extent to which the relative influences of heritable and environmental factors vary across cultures, the generalizability of our findings may also be somewhat limited. Conducting investigations similar to ours in other populations would reveal the nature of cross-cultural distinctions and commonalities in the degree to which these phenotypes are shaped by genes versus environment (and gene-byenvironment interplay). Such studies will lead to the next critical step in this line of research: the exploration of specific environmental contributions to heavy use and dependence on alcohol and cannabis, which, if they are not consistent across cultural groups, may call for differing approaches to intervention and prevention. Similarly, the modest associations between nonshared environmental influences on the 2 substances indicate that there are substance-specific environmental risk factors. The development of effective strategies for preventing misuse of alcohol and cannabis will therefore depend in part on identifying the influences on problem use that are unique to each of the 2 substances.

\section{ACKNOWLEDGMENTS}

This study was funded by grants AA007728, AA017688, AA010248, AA013320, AA13321, and AA011998 from the National Institute on Alcohol Abuse and Alcoholism and grants DA018660 and DA018267 from the National Institute on Drug Abuse.

\section{REFERENCES}

Agosti V, Nunes E, Levin F (2002) Rates of psychiatric comorbidity among U.S. residents with lifetime cannabis dependence. Am J Drug Alcohol Abuse 28:643-652.

Agrawal A, Grant JD, Littlefield A, Waldron M, Pergadia ML, Lynskey MT, Madden PAF, Todorov A, Trull T, Bucholz KK, Todd RD, Sher K, Heath AC (2009) Developing a quantitative measure of alcohol consumption for genomic studies of prospective cohorts. J Stud Alcohol Drugs 70:157-168.

Agrawal A, Lynskey MT (2006) The genetic epidemiology of cannabis use, abuse and dependence: a review. Addiction 101:801-812.

Anthony JC, Warner L, Kessler R (1994) Comparative epidemiology of dependence on tobacco, alcohol, controlled substances, and inhalants: basic findings from the National Comorbidity Survey. Exp Clin Psychpharmacol 2:244-268.

Bucholz KK, Cadoret R, Cloninger CR, Dinwiddie SH, Hesselbrock VM, Nurnberger JI Jr, Reich T, Schmidt I, Schuckit MA (1994) A new, semi- structured psychiatric interview for use in genetic linkage studies: a report of the reliability of the SSAGA. J Stud Alcohol 55:149-158.

Carney MA, Tennen H, Affleck G, DelBoca FK, Kranzler HR (1998) Levels and patterns of consumption using timeline follow-back, daily diaries and real-time "electronic interviews." J Stud Alcohol 59:447-454.

Coffey C, Carlin JB, Degenhardt L, Lynskey M, Sanci L, Patton GC (2002) Cannabis dependence in young adults: an Australian population study. Addiction 97:187-194.

Degenhardt L, Hall W (2003) Patterns of comorbidity between alcohol use and other substance use in the Australian population. Drug Alcohol Rev 22:7-13.

Elkins IJ, McGue M, Iacono WG (2007) Prospective effects of attentiondeficit/hyperactivity disorder, conduct disorder, and sex on adolescent substance use and abuse. Arch Gen Psychiatry 64:1145-1152.

Fergusson DM, Boden JM, Horwood LJ (2008) The developmental antecendents of illicit drug uses: evidence from a 25-year longitudinal study. Drug Alcohol Depend 96:165-177.

Fergusson DM, Swain-Campbell NR, Horwood LJ (2002) Deviant peer affiliations, crime and substance use: a fixed regression analysis. J Abnorm Child Psychol 30:419-430.

Gillespie NA, Neale MC, Jacobson K, Kendler KS (2009) Modeling the genetic and environmental association between peer group deviance and cannabis use in male twins. Addiction 104:420-429.

Grant JD, Agrawal A, Bucholz KK, Madden PAF, Pergadia ML, Nelson EC, Lynskey MT, Todd RD, Todorov AA, Hansell NK, Whitfield JB, Martin NG, Heath AC (2009) Alcohol consumption indices of genetic risk for alcohol dependence. Biol Psychiatry 66:795-800.

Grucza RA, Abbacchi AM, Przybeck TR, Gfoerer JC (2007) Discrepancies in estimates of prevalence and correlates of substance use and disorders between two national surveys. Addiction 102:623-629.

Hall WD, Pacula RL (2003) Cannabis Use and Dependence: Public Health and Public Policy. Cambridge University Press, Cambridge.

Hayatbakhsh MR, McGee TR, Bor W, Najman JM, Jamrozik K, Mamun AA (2008) Child and adolescent externalizing behavior and cannabis use disorders in early adulthood: an Australian prospective birth cohort study. Addict Behav 33:422-438.

Heath AC, Bucholz KK, Madden PA, Dinwiddie SH, Slutske WS, Bierut RJ, Statham DJ, Dunne NP, Whitfield JB, Martin NG (1997) Genetic and environmental contributions to alcohol dependence risk in a national twin sample: consistency of findings in women and men. Psychol Med 27:13811396.

Heath AC, Howells W, Kirk KM, Madden PA, Bucholz KK, Nelson EC, Slutske WS, Statham DJ, Martin NG (2001) Predictors of non-response to a questionnaire survey of a volunteer twin panel: findings from the Australian 1989 twin cohort. Twin Res 4:73-80.

Heath AC, Martin NG, Lynskey MT, Todorov AA, Madden PAF (2002) Estimating two-stage models for genetic influences on alcohol, tobacco or drug use initiation and dependence vulnerability in twin and family data. Twin Res 5:113-124.

Heath AC, Meyer J, Jardine R, Martin NG (1991) The inheritance of alcohol consumption patterns in a general population twin sample: II. Determinants of consumption frequency and quantity consumed. J Stud Alcohol 52:425433.

Hesselbrock M, Easton C, Bucholz KK, Schuckit M, Hesselbrock V (1999) A validity study of the SSAGA - a comparison with the SCAN. Addiction 94:1361-1370.

Hicks BM, Krueger RF, Iacono WG, McGue M, Patrick CJ (2004) Family transmission and heritability of externalizing disorders. Arch Gen Psychiatry 61:922-928.

Johnston LD, O'Malley PM, Bachman JG (2003) Monitoring the Future National Survey Results on Drug Use, 1975-2002. Volume II: College students and adults ages 19-40 (NIH Publication No. 03-5376). National Institute on Drug Abuse, Bethesda, MD.

Johnston LD, O’Malley PM, Bachman JG, Schulenberg JE (2009) Monitoring the Future National Results on Adolescent Drug Use: Overview of Key Findings, 2008 (NIH Publication No. 09-7401). National Institute on Drug Abuse, Bethesda, MD. 
Kendler KS, Karkowski LM, Neale MC, Prescott CA (2000) Illicit psychoactive substance use, heavy use, abuse, and dependence in a U.S. population-based sample of male twins. Arch Gen Psychiatry 57:261-269.

Kendler KS, Myers J, Prescott CA (2007) Specificity of genetic and environmental risk factors for symptoms of cannabis, cocaine, alcohol, caffeine, and nicotine dependence. Arch Gen Psychiatry 64:1313-1320.

Kendler KS, Prescott CA (1998) Cannabis use, abuse, and dependence in a population-based sample of female twins. Am J Psychiatry 155:10161022 .

King SM, Burt A, Malone SM, McGue M, Iacono WG (2005) Etiological contributions to heavy drinking from late adolescence to young adulthood. J Abnorm Psychol 114:587-598.

Knopik VS, Heath AC, Madden PA, Bucholz KK, Slutske WS, Nelson EC, Statham D, Whitfield JB, Martin NG (2004) Genetic effects on alcohol dependence risk: re-evaluating the importance of psychiatric and other heritable risk factors. Psychol Med 34:1519-1530.

Knopik VS, Sparrow EP, Madden PAF, Bucholz KK, Hudziak JJ, Reich W, Slutske WS, Grant JD, McLaughlin TL, Todorov A, Todd RD, Heath AC (2005) Contributions of parental alcoholism, prenatal substance exposure, and genetic transmission to child ADHD risk: a female twin study. Psychol Med 35:625-635.

Krueger RF, Hicks BM, Patrick CJ, Carlson SR, Iacono WG, McGue M (2002) Etiologic connections among substance dependence, antisocial behavior, and personality: modeling the externalizing spectrum. J Abnorm Psychol 111:411-424.

Kuperman S, Schlosser SS, Kramer JR, Bucholz KK, Hesselbrock V, Reich T, Reich W (2001) Developmental sequence from disruptive behavior diagnosis to adolescent alcohol dependence. Am J Psychiatry 158:20222026.

Li T-K (2008) Quantifying the risk for alcohol-use and a;cohol-attributable health disorders: present findings and future research needs. J Gastroenterol Hepatol 23(Suppl. 1):S2-S8.

Li T-K, Hewitt BG, Grant BF (2007) Is there a future for quantifying drinking in the diagnosis, treatment, and prevention of alcohol use disorders? Alcohol Alcohol 41:57-63.

Lynskey MT, Heath AC, Bucholz KK, Slutske WS, Madden PAF, Nelson EC, Statham DJ, Martin NG (2003) Escalation of drug use in early-onset cannabis users vs co-twin controls. JAMA 289:427-433.

Lynskey MT, Heath AC, Nelson EC, Bucholz KK, Madden PAF, Slutske WS, Statham DJ, Martin NG (2002) Genetic and environmental contributions to cannabis dependence in a national young adult twin sample. Psychol Med 32:195-207.

Marshal MP, Molina BSG, Pelham WE Jr (2003) Childhood ADHD and adolescent substance use: an examination of deviant peer group affiliation as a risk factor. Psychol Addict Behav 17:293-302.

McBride O, Adamson G, Bunting B, McCann S (2009) Diagnostic orphans: comparing self-report lifetime course to groups with DSM-IV alcohol abuse and dependence. Addict Behav 34:86-91.

McGue M, Iacono WG, Krueger R (2006) The association of early adolescent problem behavior and adult psychopathology: a multivariate behavioral genetic perspective. Behav Genet 36:591-602.

Miles DR, van den Bree MBM, Pickens RW (2002) Sex difference in shared genetic and environmental influences between conduct disorder symptoms and marijuana use in adolescents. Am J Med Genet 114:159168.

Monshouwer K, van Dorsselaer S, Verdurmen J, Bogt TT, de Graaf R, Vollebergh W (2006) Cannabis use and mental health in secondary school children. Br J Psychiatry 188:148-153.

National Center for Health Statistics (2009) Health, United States, 2008. Chartbook, Hyattsville, MD.

Neale MC, Boker SM, Xie G, Maes HH (2003) Mx: Statistical Modeling, 6th ed. Virginia Commonwealth University, Richmond, VA.

Nelson EC, Heath AC, Madden PAF, Cooper ML, Dinwiddie SH, Bucholz KK, Glowinski A, McLaughlin T, Dunne MP, Statham DJ, Martin NG (2002) Association between self-reported childhood sexual abuse and adverse psychosocial outcomes: results from a twin study. Arch Gen Psychiatry 59:139-145.

Nocon A, Wittchen H-U, Pfister H, Zimmermann P, Lieb R (2006) Dependence symptoms in young cannabis users? A prospective epidemiological study J Psychiatr Res 40:394 403

O'Neill SE, Parra GR, Sher KS (2001) Clinical relevance of heavy drinking during the college years: cross-sectional and prospective perspectives. Psychol Addict Behav 15:350-359.

Pape H, Rossow I, Storvoll EE (2009) Under double influence: assessment of simultaneous alcohol and cannabis use in general youth populations. Drug Alcohol Depend 101:69-73.

Reed T, Page WF, Viken RJ, Christian JC (1996) Genetic predisposition to organ-specific endpoints of alcoholism. Alcohol Clin Exp Res 23:15281533

Saha TD, Stinson FS, Grant BF (2007) The role of alcohol consumption in future classifications of alcohol use disorders. Drug Alcohol Depend 89:8292.

Sartor CE, Agrawal A, Lynskey MT, Bucholz KK, Madden PAF, Heath AC (2009) Common genetic influences on the timing of first use for alcohol, cigarettes, and cannabis in young African-American women. Drug Alcohol Depend 102:49-55.

Sherman DK, Iacono WG, McGue MK (1997) Attention-deficit hyperactivity disorder dimensions: a twin study of inattention and impulsivityhyperactivity. J Am Acad Child Adolesc Psychiatry 36:745-753.

Slutske WS, Heath AC, Dinwiddie SH, Madden PA, Bucholz KK, Dunne MP, Statham DJ, Martin NG (1998) Common genetic risk factors for conduct disorder and alcohol dependence. J Abnorm Psychol 107:363374.

Stinson FS, Ruan WJ, Pickering R, Grant B (2006) Cannabis use disorders in the USA: prevalence, correlates and co-morbidity. Psychol Med 36:14471460

Stockwell T, Donath S, Cooper-Stanbury M, Chikritzhs T, Catalano P, Mateo C (2004) Under-reporting of alcohol consumption in household surveys: a comparison of quantity-frequency, graduated-frequency and recent recall. Addiction 99:1024-1033.

Substance Abuse and Mental Health Services Administration (2002) Results from the 2001 National Household Survey on Drug Abuse, Volume I Summary of National Findings. Office of Applied Studies, NHSDA Series H-17, DHHS Publication SMA 02-3758, Rockville, MD.

Teesson M, Baillie A, Lynskey M, Manor B, Degenhardt L (2006) Substance use, dependence and treatment seeking in the United States and Australia: a cross-national comparison. Drug Alcohol Depend 81:149-155.

True WR, Heath AC, Bucholz KK, Slutske W, Romeis JC, Scherrer JF, Lin N, Eisen SA, Goldberg J, Lyons MJ, Tsuang MT (1996) Models of treatment seeking for alcoholism: the role of genes and environment. Alcohol Clin Exp Res 20:1577-1581.

True WR, Heath AC, Scherrer JF, Xian H, Lin N, Eisen SA, Lyons MJ, Goldberg J, Tsuang MT (1999) Interrelationship of genetic and environmental influences on conduct disorder and alcohol and marijuana dependence symptoms. Am J Med Genet 88:391-397.

van den Bree MBM, Johnson EO, Neale MC, Pickens RW (1998a) Genetic and environmental influences on drug use and abuse/dependence in male and female twins. Drug Alcohol Depend 52:231-241.

van den Bree MBM, Johnson EO, Neale MC, Svikis DS, McGue M, Pickens RW (1998b) Genetic analysis of diagnostic systems of alcoholism in males. Biol Psychiatry 43:139-145.

Whitfield JB, Zhu G, Madden PAF, Neale MC, Heath AC, Martin NG (2004) The genetics of alcohol intake and of alcohol dependence. Alcohol Clin Exp Res 28:1153-1160.

Xian H, Scherrer JF, Grant JD, Eisen SA, True WR, Jacob T, Bucholz KK (2008) Genetic and environmental contributions to nicotine, alcohol and cannabis dependence in male twins. Addiction 103:1391-1398.

Young SE, Rhee SH, Stallings MC, Corley RP, Hewitt JK (2006) Genetic and environmental vulnerabilities underlying adolescent substance use and problem use: general or specific? Behav Genet 36:603-615. 


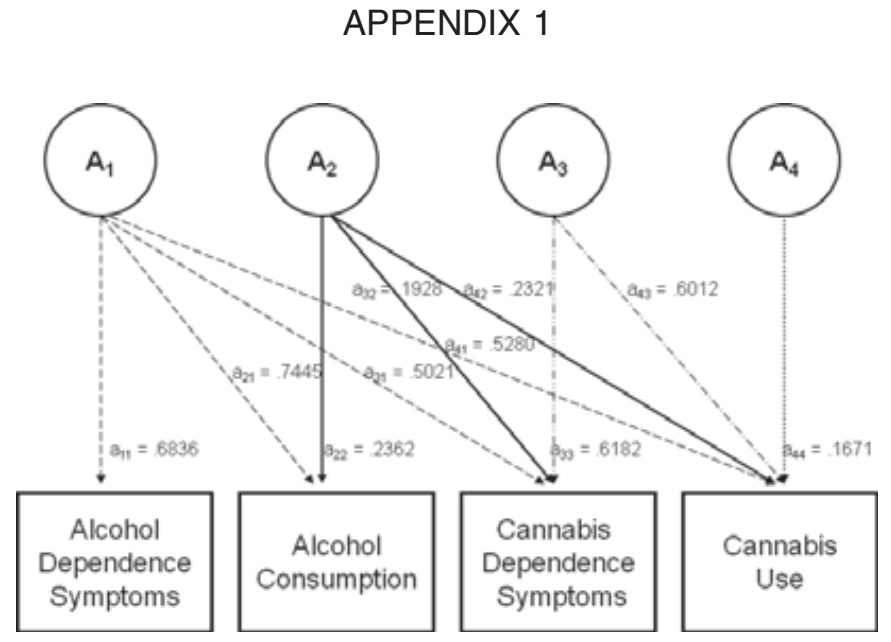

Unstandardized Additive Genetic Path Estimates for the 4 Phenotypes.

Raw path estimates are shown.

Calculation of genetic variance from common and specific sources is illustrated below for cannabis dependence symptoms:

Total genetic variance $=(0.6182)^{2}+(0.1928)^{2}+(0.5021)^{2}$ $=0.6715$.
Variance explained by A1 (genetic influences common to all 4 phenotypes $)=(0.5021)^{2} / 0.6715=0.3754^{*}$.

Variance explained by A2 (genetic influences shared by alcohol consumption, cannabis dependence symptoms, and cannabis use $)=(0.1928)^{2} / 0.6715=0.0554^{* *}$.

Variance explained by A3 (genetic influences common to cannabis dependence symptoms and cannabis use $)=(0.6182)^{2} /$ $0.6715=0.5691$.

*From Table 6, the genetic correlation between alcohol dependence symptoms and cannabis dependence symptoms is 0.6128 , which is computed as $\sqrt{ } 0.3754$.

**From Table 6, the genetic correlation between alcohol consumption and cannabis dependence symptoms is 0.6558 . This is NOT equal to $\sqrt{ } 0.0554$. To calculate this correlation, we compute the total genetic covariance across the 2 measures, including variance shared with alcohol dependence symptoms, and divide it by the product of the square root of the total genetic variance in alcohol consumption and cannabis dependence symptoms.

Therefore, $0.6558=(0.2362 \times 0.1928)+(0.7445 \times 0.5021)$ $[(\sqrt{ } 0.6715) \times(\sqrt{ } 0.6100)]$, where $0.6100=(0.2362)^{2}+(0.7445)^{2}=$ the total genetic variance in alcohol consumption explained by $\mathrm{A} 1$ and $\mathrm{A} 2$. 